\title{
Content service management: Turning digital assets into commercial services
}

\author{
Keith Kocho \\ is the founder and CEO of ExtendMedia, a leading provider of software solutions to the digital content and media \\ industry. For the past 15 years, ExtendMedia has worked closely with the world's most successful and innovative \\ communications and media companies to design, deploy and commercialize consumer content services across a wide \\ array of distribution networks and connected devices.
}

Keywords: content service management, distribution, business rules, digital rights management (DRM), triple play

Abstract Content service management is a new class of software that is of critical importance to content companies struggling with an increasingly complex media distribution landscape. It picks up where asset management systems leave off, providing the infrastructure to commercialize the asset and deliver it as part of a service into a multivariate distribution environment. As a result, the defining features of content service management solutions are (1) workflow and automation to manage the "asset-to-service lifecycle," (2) the application and enforcement of business rules, and (3) hooks into the operational support infrastructure.

Keith Kocho

CEO

ExtendMedia

190 Liberty Street

2nd Floor

Toronto

Ontario M6K 3 L5

Canada

Tel: +14165354222

Fax: +14165351201

Email:

kkocho@extend.com

\section{INTRODUCTION}

Once upon a time, getting content into the hands of consumers was a relatively simple and well understood proposition. Large, facilities-based distributors primarily broadcasters, cable operators, and satellite operators - dominated the landscape, aggregating content and delivering it to the mass market. Content companies syndicated their product to these distributors using equally simple methods - tape, broadcast, satellite - technologies that in one form or another had been around for decades.

How things have changed. Content companies now face an increasingly complex distribution landscape, delivering into traditional linear video environments, on-demand environments, over broadband networks, and wirelessly to mobile handsets.

For their part, the distributors' world has also become trickier. No longer are cable companies just video service providers - indeed their internet businesses have been an engine of growth for some time now. And while their current telephony launches may have limited implications for media distribution, the upcoming wireless deployments will be a significant development. And let's not forget that the telecoms companies themselves - already wireless and internet players - are in the process of launching internet protocol television (IPTV) services to compete head to head with cable. 


\section{MARKET TRENDS}

Three major trends are shaping this emerging media distribution landscape:

- facilities-based competition;

- the disintermediation of distributors;

- new entrants - PC, consumer electronics (CE) and the internet.

\section{Facilities-based competition}

This is the most obvious trend in the industry, mainly because it has been so widely covered in the mainstream media. Simply put, cable operators and telecoms are gripped in a high-stakes land grab that's increasingly blurring the lines between the two classes of competitor.

Cable operators kicked off the trend by launching telephony - primarily based on voice over internet protocol (VoIP) technology. By any yardstick, VoIP has already been quite a success for operators thus far. For example, Cablevision Systems in New York, only 18 months after launch, now has approximately half a million VoIP subscribers - approaching 20 per cent of its cable subscriber base.

The larger telecoms - SBC, Verizon, Bell South - have all responded with announcements of upcoming IPTV services. While actual deployments in the USA are relatively small, just look across the 49th parallel to Canada for a glimpse of what's coming. For example, MTS - the incumbent telecom in Manitoba - is approaching 15 per cent of the Winnipeg market, where its MTS television service has been deployed for nearly two years. In that market, MTS was actually the first mover - the incumbent cable operator just launched its VoIP service in Winnipeg this quarter.
Clearly, this competition between "natural" facilities-based competitors incumbent telecoms and cable operators operating in the same market — is spurring innovation. In addition to linear channels, both competitors now offer video on demand (VOD) as a basic service. Companies such as Cablevision have launched video-enhanced interactive television channels.

Meanwhile, satellite competitors are starting to use their digital video recorders (DVRs) to cache video in the home, as a competitive response to the VOD services they have difficulty launching on their one-way architecture.

For the content company, this spells headache. Each competitor has its own methods of getting content into the system from suppliers. For example, while the cable industry has largely standardized around CableLabssponsored initiatives like ADI (a specification for delivering VOD content), it is still uncertain whether the telecoms will follow suit.

This doesn't even begin to take into account wireless content delivery. The cable operators are getting increasingly aggressive with mobile virtual network operator (MVNO) services. By leasing wireless capacity wholesale, they are attempting to put the capstone on their strategy to compete head to head with the telecoms. As long-time content aggregators, expect them to deploy wireless content services aggressively. For proof, look again to Canada, where Rogers Communications is both the country's largest cable operator and largest wireless provider. In the last few months, Rogers has launched both wireless music and video services to mobile handsets, with major marketing campaigns supporting the launch. 
Two more wrinkles in the pudding before we move on. The first of these, WiMax, the underlying economics of which will potentially enable a rush of new entrants - each delivering broadband connectivity and a suite of IP-based services - internet, VoIP and IPTV.

The second is national competition among local monopolies. As more services move to an IP deployment model, owning a network is no longer a prerequisite to delivery of a content service. Consider UK-based Home Choice, which provides linear and interactive television, VOD and broadband service to over 15,000 subscribers in the London M25 area all overlaid on a network BT controls.

Within the next 12 months, expect to see several cable operators in North America launch commercial broadband video services within and outside of their network footprint. Initial efforts will likely focus on broadband video, but ultimately these will migrate to full IPTV services. For the first time, these companies will be competing directly with one another - a dynamic that should further spur competitive innovation internally while potentially weakening industry standards bodies like CableLabs. This can only further complicate the distribution landscape.

\section{The disintermediation of distributors}

Of course, the Home Choice model doesn't just apply to network operators. Increasingly, large branded content companies are deploying commercial video services directly to the consumer. The motivation is mainly economic many of these companies feel they're not adequately compensated for their content by now-behemoth cable operators that have all the leverage in the relationship. Ditto for physical distribution, where Wal-Mart - now the largest DVD retailer - famously negotiates suppliers down to razor thin margins.

Examples are increasingly common. Starz now offers 150 new release movies via broadband download. CBS has announced a 24/7 broadband video channel. ESPN pushes high-quality video to a local cache on the consumer's PC. ESPN is also launching an MVNO wireless service, with branded handsets providing instant access to ESPN content. The company has said it is considering a similar play with broadband-ready television sets.

For a glimpse at how such a service might operate, look at XTV, an adult video service currently deployed in the USA and Canada. For US\$30 per month, XTV gives its customers a small set-top box that provides access to 70 channels of streaming video, hundreds of premium VOD titles, and interactive features. The service relies on a "bring your own broadband" model - plugging in an ethernet cable and running RCA jacks out to the television is all the setup that's required.

\section{New entrants: PC, consumer electronics, and the internet}

For a long time now, the popular press has talked about the convergence of television and the internet, and for a long time it's made nice copy but little market headway. Yet the conditions are finally right for that to change, driven by three factors:

- the increased penetration of broadband; 
- advances in video compression (H.264, VC1 etc); and

- the increasing availability, sophistication — and often storage capacity - of networked CE devices.

One does not have to look far for evidence of this trend. Apple, in about two years, mopped up 80 per cent of the digital music marketplace by tying a smart CE device (the iPod) to a smart content service (the iTunes Music Store). Recent reports confirm a longanticipated move into video - Steve Jobs is, after all, the head of a studio.

Similarly, the big surprise about the Sony PSP (PlayStation Portable) has been how many content providers are delivering PSP-compatible media to the device. Like a video-capable iPod, the PSP is fast becoming a portable media consumption device.

TiVo has announced a deal with Netflix to deliver an IP-based VOD service directly to the DVR. Just this week, the Independent Film Channel announced plans to release a new series direct to TiVo.

Then there's Microsoft, which arguably has the most comprehensive and far-reaching approach to this market, based around the Microsoft Media Center as a hub device for media aggregation and routing within the connected home. While there are currently only two million Media Center PCs in the market, the launch of the Media Center environment on the upcoming XBox 360 will dramatically change that picture. Microsoft has also syndicated the platform to a suite of connected and portable devices through its Extender software. And let's not forget the fact that many of the top telecoms have licensed their
MicrosoftTV IPTV edition middleware platform — which includes a modified version of the Media Center.

As if delivering content into these new device environments doesn't present enough distribution challenges for the content company, there's more.

Yahoo is moving aggressively to transform itself from an online directory to an entertainment portal. With a registered user-base eight times larger than Comcast, they're not a force to be ignored. Recent rentals of top Hollywood talent have been supplemented with deals to distribute video through the Microsoft Media Center, as well as the launch of a developer program to enable third parties to make Yahoo content and services accessible to their internetenabled stereos, televisions and other home electronic devices.

Google, meanwhile, is positioning itself as the cable company of the future, and this year has rolled out two technologies that will be critical to their success. The first is a personalization infrastructure that enables targeting of content based on consumer preference. The second is Google Video, which turns the company's search engine into a flexible storefront for media, while providing content companies with the means to manage their offering within that window. Google, of course, takes a cut of the sale.

\section{CONTENT SERVICE MANAGEMENT}

We won't attempt to add up all of the potential distribution channels available to content companies, but by now the challenges they will face going forward should be clear. And while their investments to date in digital asset 
management (DAM) systems greatly enhance their capacity to produce and store assets for these new environments, such systems are not, in and of themselves, sufficient to help content companies to commercialize these assets in a multivariate distribution environment.

That's where content service management comes in. It picks up where asset management systems leave off, controlling the workflow and automation necessary to manage the "asset-to-service lifecycle," including the application and enforcement of business rules and hooks into an underlying operational support system (OSS).

In fact, the best way to think about content service management is as the glue between DAM systems and OSS the link between assets and commercial services.

A content service management system may be purchased from a single vendor, or assembled internally from best of breed technologies. In either case, the following sections will describe the base functionality and business use cases such a system should support.

\section{Command and control}

Content service management systems allow content companies to define sophisticated business rules to master every aspect of the content service lifecycle - controlling ingestion, metadata, encoding, encryption, packaging, pricing, distribution and promotion from a single, workflowdriven interface. In some implementations, elements of the system may also be exposed externally, extending that workflow to distributors, suppliers and other business partners.

From a business process standpoint, ingestion of assets and metadata is typically the first step. The originating source might be a DAM system or one or more external providers, but in all cases metadata will need to be normalized - translated into an internal metadata specification that represents a superset of the metadata required for all of the varying distribution channels and potentially edited. Because new channels are emerging all the time, it is critical that the internal metadata specification be extensible, and that the metadata export formats be pluggable. A company that today only distributes to cable VOD using CableLabs ADI may find themselves in the future requiring OMA metadata for wireless, TV-Anytime metadata for DVR support, Google Video metadata and a custom scheme to run their own directto-consumer broadband service.

The second step of the process is typically encoding, as with every different distribution channel comes different encoding requirements. Once the requirements for a particular channel have been established, however, they will not often change, providing an ideal opportunity for automation. A content service management system enables companies to set business rules to automate the re-encoding or transcoding of assets and trigger the encoding process on the external encoders.

The third phase is packaging. While assets may be delivered as standalone products in on-demand environments, they may also be packaged as part of a service. A popular example of this is subscription video on demand (SVOD) in which a bouquet of assets is made available to consumers for a single monthly fee. A variant of this model might allow consumers to purchase a 
monthly subscription to, say, any five titles from the library. Consumptionbased billing (based on minutes or titles), download-to-own, or token-based billing (utilizing credits or loyalty points) are some other options available. Additionally, there may be non-pricing based product rules such as prerequisite services or membership in a specific target group (gold customers, Comcast digital subscribers, etc). The content service management system should be flexible enough to handle such business rules and pricing models from a single interface.

For the fourth phase, assets need to be encrypted. Although for some channels encryption may be provided by a thirdparty distributor such as a cable company, other channels (especially direct-to-consumer) will require the content company to encrypt assets themselves. Typically, this is handled through external digital rights management (DRM) solutions provided by such companies as Microsoft, Real Networks, Beep Science, etc. The content service management system should provide out-of-the-box support for the major DRM technologies, as well as a pluggable security framework for adding new technologies as the market emerges.

The fifth phase is distribution, which as we've already seen, is a point of particular complexity. Again, automation can provide significant efficiency advantages here as, once the channel is set up, the parameters do not often change. The content service management system should support a wide array of distribution environments — including unicast, broadcast, multicast and such peer-based delivery systems as super-distribution. It should also enable both direct and indirect distribution models, allowing content companies to use the same system, for example, to deliver their own branded broadband or wireless service as they do for cable or telecoms VOD environments.

The final phase is promotion. The content service management system should allow the content company to define targeted promotional campaigns for content and services, with a goal of turning every point of presence into a point of sale. Promotional offers may be triggered based on customer characteristics or specific behavior, and might consist of discounts, free trials or services, or loyalty points.

\section{Operational support}

We said earlier that content service management is the glue between DAM systems and OSS. In fact, the system may actually provide underlying OSS functionality either on a standalone basis or in conjunction with existing backoffice systems. That's because the business use cases traditional OSS systems were designed to meet are often ill-suited for the challenges of the emerging distribution landscape.

Take subscriber management for example. Traditional systems designed for network operators are well suited to manage basic account information such as name, address, subscribed services and transaction history. However, they do not provide any intuitive understanding of the customer's preferences, their usage patterns for services, or the connected devices with which they consume content. This is critical to providing the granular customer segmentation capabilities that allow content companies to run the sort of targeted micro- 
promotions described above.

Additionally, subscriber management systems typically structure account information either on a household basis (eg for cable companies) or an individual basis (eg for wireless companies), but may not provide a hierarchical structure to handle an increasingly common hybrid in which individual services are delivered within a household account.

One final consideration here is identity management. It is possible, even likely, that the content service management system will not be the subscriber system of record for every service a company provides. Legacy services may exist, or the service may be distributed through a partner. In these scenarios, it is recommended that the content service management system support such federated identity standards as Liberty Alliance, OASIS, and Microsoft Passport. This will allow for secure sharing of identity information, enabling single sign-on across services and delivering a more seamless experience for consumers.

A second critical OSS area is billing. As with subscriber management systems, traditional billing systems are not always appropriate for the types of services content companies will be called on to deliver going forward. For example, many cable billing systems cannot handle micro-payments, consumptionbased services or loyalty points. Alternatively, the product catalogues may not be flexible enough to handle the complex packaging rules the content company would like to create. In these situations, the content service management system may be the only way to deliver such services.

Of course, there may be a suitable billing system in place already, so it is imperative that the content service management system be able to leverage these facilities where available while providing a complete solution where they are not.

To do this requires that the system contain extensive transaction management capabilities. It will need to collect low-level customer transactions/ events and mediate them into chargeable products and services. It will need rating capabilities to support the disparate pricing and promotion models outlined above. It will need to clear the transaction by submitting the mediated, rated charges to a credit card gateway, billing system, or other payment processing system. And it may even need to feed data into a financial accounting or enterprise resource planning (ERP) package - a requirement which entails internal double-entry accounting capabilities within the content service management system.

There is other OSS functionality that also needs to be considered, much of which is implied by the workflow and automation system described above.

For example, the DRM framework needs to be tied into the OSS environment to provide for authentication and access to content. Similarly, the physical distribution architecture - streaming servers, multicast publishing points, network policy servers, etc - is a fundamental piece of the puzzle, and the content service management system may contain, or interface with, these as well.

\section{FUTURE DIRECTIONS}

Content service management will be a major investment area for content companies and distributors alike over the 
next 24 months. These solutions provide a comprehensive infrastructure to commercialize the asset and deliver it as part of a service into a multivariate distribution environment.

In the above discussion, the term commercialize is used largely to refer to consumer revenue streams. This is intentional, because capturing these streams is currently a major strategic focus of content companies addressing the emerging landscape.

As these services mature, however, it will be necessary to open up supplemental revenue streams as well. For obvious reasons, advertising is the most important of these, and content service management systems are well suited to deliver a comprehensive advertising solution by extending existing functionality.

For example, ingesting ads and associated metadata can operate in a similar manner to that described for content assets. Similarly, campaign rules may be controlled in a manner similar to the productization and packaging rules for content assets. Insertion is an extension of the content distribution architecture, which provides for rules- and profile-based delivery of assets in disparate distribution environments - and can do the same for advertising.

From a management and production standpoint, this approach ensures that workflow and business tools are consistent across the content service management interfaces.
Perhaps the most interesting application of this approach is in the area of DRM-based advertising. Although DRM is typically thought of in terms of content security and encryption, its real strengths are in business rules management and policy enforcement which in the case of a content service management system is tied directly into the OSS infrastructure. By encrypting advertisements using DRM, content providers can leverage this infrastructure.

For example, encrypted advertising can function as an electronic coupon for discounts on programming subsidized by sponsors in exchange for fulfilling certain conditions (eg watching an ad). The content service management system can then enforce "must-watch" and other business rules specified in the offer, authorize the discount once the conditions have been met, and handle all of the financial reconciliation and success tracking.

In addition, coupons might be detached from the original programming and forwarded to other subscribers, opening up new viral marketing opportunities.

Clearly other models will emerge as media buyers start to see the potential of this technology. With a robust content service management system in place, content companies are well positioned to capitalize on these emerging opportunities, driving a better service experience for customers and new revenues for their business. 